\title{
PATRONES CULTURALES DEL PERIODISMO DE FUENTES: LA GESTIÓN DE LA COMUNICACIÓN SOBRE EMERGENCIAS EN LA ADMINISTRACIÓN PÚBLICA EN ESPAÑA. LA CRISIS DEL ÉBOLA Y EL TERREMOTO DE LORCA
}

Cultural Patterns of the Source Based Journalism. The Management of Communication about Emergencies in the Spanish Public Administration. The Ebola Crisis and the Earthquake in Lorca

Patrões culturais do jornalismo de fontes: a gestão da comunicação sobre emergências na administração pública na Espanha. A crise do Ebola e o terremoto de Lorca

IBÁÑEZ, Ángel. Universidad Complutense de Madrid. (España) angelip2003@hotmail.com

Fecha de recibido: 21 de julio de 2015

Fecha de aceptado: 04 de noviembre de 2015 


\section{RESUMEN}

La actividad de informar no solo se circunscribe a la captación y difusión de información; existe una especialidad, rama, o cultura, denominada 'Periodismo de fuentes' que consiste en suministrar los datos oportunos tanto al público en general como a los periodistas de los Medios que, de forma directa, informan a los ciudadanos. Los profesionales que ejercen esta rama o cultura periodística, en la actualidad, suelen ser los llamados Directores de Comunicación (DIRCOM).

Para la Administración, la función de informar es un precepto legal, consecuencia del artículo 20 de la Constitución. De este se deriva el derecho ciudadano a la información sobre las actividades de la Administración, sean generales o particulares, conforme a los derechos fundamentales de cualquier persona. Como consecuencia de ello, la Administración es una fuente de información para los profesionales del periodismo.

En el presente trabajo se tratan las peculiaridades que pueden observarse al examinar la normativa referente a la función pública de informar en el ámbito de la Administración y las vicisitudes a que están sometidos los Directores de Comunicación encargados de ello. Como casos prácticos se analizan la gestión de la Información Pública durante el terremoto ocurrido en Lorca en 2011, y el desarrollo de la crisis mediática que se produjo en España derivada del virus del Ébola en 2014.

Palabras clave: Administración, Información Pública, emergencias, crisis mediáticas, Ébola, Terremoto de Lorca.

\section{ABSTRACT}

The activity of informing is not only based on getting the information; there is a branch or culture called "Source journalism" that provides data to journalists, who report directly to citizens. It is known as "source journalism" because it is done from the information source. The professionals affiliated to this branch or journalistic culture are usually the so-called Communication Directors (DIRCOM).

For the administration, the function of informing is an obligation based on the $20^{\text {th }}$ article of the Constitution. From that article derives the right of the citizens to get information about the activities of the administration, those activities can be general or particular according to the interests or fundamental rights of a person. As a consequence, the administration is an information source for journalists.

This work is about the peculiarities of performing the public function of informing as part of the administration and about the vicissitudes to which Communication Directors are subjected. The practical cases analyzed are the management of the Public Information during the Lorca earthquake in 2011 and the media crisis in Spain derived from the Ebola virus in 2014.

Keywords: Administration, public information, emergencies, media crisis, Ebola, Lorca earthquake. 


\section{RESUMO}

A atividade de informar não só se circunscreve à captação e difusão de informação, existe uma especialidade, ramo, ou cultura, que denominada "Jornalismo de Fontes" consiste em fornecer os dados oportunos tanto ao público em geral quanto aos jornalistas dos meios que, de forma direta, informam aos cidadãos. Os profissionais que exercem este ramo ou cultura jornalística, na atualidade, costumam ser os chamados Diretores de Comunicação (DIRCOM).

Para a Administração, a função de informar é um preceito legal, consequência do artigo 20 da Constituição. Dele deriva-se o direito cidadão à informação sobre as atividades da Administração, sejam gerais ou particulares, conforme a interesses e direitos fundamentais de qualquer pessoa. Como consequência disso, a Administração é uma fonte de informação para os profissionais do jornalismo.

No presente trabalho tratam-se peculiaridades que podem se observar ao examinar a normativa referente à função pública de informar no âmbito da Administração e as vicissitudes a que estão submetidos os Diretores de Comunicação encarregados disso. Como casos práticos se analisa a gestão da Informação Pública durante o terremoto ocorrido em Lorca em 2011, e no desenvolvimento da crise mediática que se produziu na Espanha derivada do vírus do Ebola no ano 2014.

Palavras-chave: Administração, Informação Pública, emergências, crises mediáticas, Ebola, Terremoto de Lorca

\section{Introducción}

El derecho a la información, es uno de los derechos fundamentales del hombre, facilita su existencia y tiene un valor supremo, hasta el punto de haber sido elevado a la categoría derecho positivo, con capacidad de regular una actividad social como es la de la información. La información es un bien que pertenece a todos, es una función pública y

nadie puede informar si no cumple una función informativa. Nadie puede ejercitar el derecho a la información si no es dentro del Derecho de la Información, si no es para cumplir la justicia informativa, la realización del suum en que la información consiste (Desantes, 1976, p. 153).

De esta forma, para la Administración, la gestión de la información ${ }^{1}$ es una función pública más a la que tiene que hacer frente con transparencia e igualdad. Por ello, la Administración se convierte en el principal agente

1 Para la Administración, los términos información y comunicación no se corresponden con lo que entre el gran público se considera al respecto (Ibáñez, 2014, p. 26). Así las cosas, en el presente trabajo se van a considerar ambos términos -comunicación e información- como el objeto de la función pública de informar, con la cual la Administración difunde datos sobre las cuestiones que afectan a la comunidad 
difusor de la información en todo lo que a ella le afecte, debiendo presidir la idea de que al ser la información en sí misma una función pública, con independencia de que sus agentes sean públicos o privados, los informadores, periodistas y empresarios de la información no tienen más derecho a ella que el resto de las personas. "La propiedad de un medio de comunicación social no conlleva el derecho de propiedad de la información. (...) El titular del poder de la información es el pueblo". (Nieto, 1987, pp. 108 y 110)

El informador, en lo que toca al derecho a la información, es el instrumento en el que ha delegado la sociedad, y en particular su público, la realización del deber profesional de informar; cumpliendo ese deber, se hace posible que la participación de los ciudadanos en los asuntos públicos sea más fácil. Así, la Administración se convierte en el informador y los administrados en el público al que se debe informar. Esta función pública se hace efectiva con el ejercicio de la profesión periodística que, con marcadas diferencias respecto al periodismo que se realiza en el sector privado, conlleva una especialización del personal al que se le encomiendan estas labores informativas.

En situaciones de grave amenaza social la Administración debe manejar un conjunto de factores y de actores que interaccionan en la forma de gestionar la información a la población; el ordenamiento jurídico español, el de la Unión Europea, las particularidades de los distintos niveles administrativos (Local, Autonómico y Central), así como los intereses políticos, componen el grueso de esos factores. Pero no se debe perder de vista que en circunstancias como las aludidas, relacionadas con la seguridad de las personas, el derecho a la información se subordina al derecho a la vida; conforme a esto, cuando está en peligro la vida humana, tanto a los medios de comunicación como a los informadores se les debe exigir que actúen con extrema cautela y con las limitaciones éticas propias de un estado de excepción hasta el punto de que

los medios de comunicación están obligados a colaborar de manera gratuita con las autoridades en la difusión de las informaciones preventivas y operativas ante los riesgos y emergencias en la forma que aquéllas les indiquen y en los términos que se establezcan en los correspondientes planes de protección civil (Ley 17/2015 del Sistema Nacional de Protección Civil, artículo 8).

Dicho lo cual surgen, entre otras, las siguientes reflexiones: ¿por qué se producen crisis mediáticas como las que se dieron en la gestión informativa del terremoto de Lorca en 2011 o los dos casos del Ébola ocurridos en España en el año 2014?, ¿por qué durante los primeros momentos la Administración no se convirtió en fuente de información dejando la iniciativa a los medios de comunicación privados?, ¿estas irregularidades son el resultado de la imprevisión y mala gestión en materia de Información Pública por parte de las distintas Administraciones?

utilizando los medios de comunicación de masas para que los ciudadanos vean cumplido el derecho a la información que les asiste. Función pública de informar, que al ser ejercida de forma exclusiva por la Administración y tener ciertas características particulares, de obligado cumplimiento, que la diferencian de la información difundida por los medios de comunicación privados se convierte en una realidad única, motivo por el que se denominará Información Pública (con mayúsculas iniciales) y a cada una de las entidades que la gestionan: órgano de comunicación. 


\subsection{Objeto de estudio y planteamiento metodológico}

El propósito de este trabajo es determinar la forma en que se ejerce el periodismo de fuentes en la Administración, y por ello conocer el estado y la forma en que se gestiona la Información Pública² en situaciones de catástrofes, crisis y emergencias.

Las técnicas de investigación utilizadas han consistido en la consulta de fuentes documentales u observación documental (legislación, estadísticas, medios de comunicación, etc.) y la utilización de los datos obtenidos mediante una encuesta, pues se entiende que, al no disponer de los datos necesarios, la encuesta es el sistema más propicio para fundamentar las conclusiones cuando no pueden ser extraídas de la experimentación o de la observación directa.

Así las cosas, el estudio abarca tres aspectos. El primero se centra en el marco legal en que la Administración debe gestionar la Información Pública en los casos de emergencia y su conexión con el periodismo de fuentes. Dada la diversidad de competencias entre las distintas Administraciones del Estado, el estudio se ciñe principalmente a la normativa relativa a la Administración General del Estado.

El segundo aspecto estudiado es el relativo a las características del personal que ejerce en la Administración el periodismo de fuentes en situaciones de catástrofe o emergencia. Aunque existen diversos trabajos relativos a la comunicación en la Administración, como puede ser el publicado por Canel (2007) o los de ADC DirCom (2007), ninguno de ellos estudia la Información Pública en emergencias. Por otra parte, es conveniente significar que los estudios hechos en el marco de la Administración y tutelados por la Dirección General de Protección Civil, se limitan a las guías técnicas sobre comunicación de riesgos publicadas en 1991 y 2001, así como el titulado Análisis de la demanda de información y elaboración de un modelo guía de respuesta (Dirección General de Protección Civil y Emergencias, 2004). Estos estudios han quedado obsoletos y por tanto no se han podido utilizar en este trabajo. Ante la imposibilidad de encontrar alguna investigación que se ajuste a los parámetros definidos por los términos 'Administración Pública' y 'comunicación en catástrofes o emergencias', se ha recurrido a una encuesta que como trabajo de campo ha realizado el autor y que forma parte de la tesis titulada: Comunicación, Administraciones Públicas y gestión de crisis y emergencias (Ibáñez, 2014).

El tercer aspecto se ha centrado en el análisis de dos casos prácticos: el terremoto ocurrido en Lorca en 2011 y la crisis del Ébola de 2014. Estos han sido utilizados como sendos barómetros para conocer el grado de cumplimiento, por parte de la Administración, de lo que el marco jurídico determina en materia comunicacional. Para ello se ha seguido y analizado lo publicado al respecto en la prensa escrita, y las noticias difundidas por los órganos de

2 Para poder abordar la materia de forma sencilla y sin entrar en disquisiciones técnicas sobre los conceptos de comunicación e información, que pueden dispersar la atención sobre el objeto que nos ocupa, de forma simplista vamos a convenir que, en el campo de las crisis y la emergencia, la comunicación es la información que ha llegado al público destinatario para el que fue elaborada y ha causado los efectos perseguidos; es decir, la información se convierte en comunicación cuando es "aprovechada" por el público al que va dirigida. Y así, se puede afirmar que, la Comunicación Pública es la Información Pública que ha alcanzado el más alto grado de efectividad al haber conseguido el objetivo que se pretendía con su difusión. 
comunicación de la Administración, como fuente de información, mediante sus notas y comunicados de prensa a través de sus páginas web.

\section{La Administración como fuente de información en emergencias. Marco legal}

La Información Pública suele englobar dos aspectos, el que surge como consecuencia de los idearios políticos del Gobierno de turno, que se puede calificar como propaganda política, y el derivado de la gestión de ese Gobierno ${ }^{3}$ como poder ejecutivo de una sociedad que lo ha elegido mediante su voto en las urnas. Esta "dualidad entre la naturaleza política y ejecutiva de la acción gubernamental debe mantenerse en esferas comunicativas separadas" (Ley 29/2005, Exposición de motivos). Y así, la labor informativa del Gobierno se debe llevar a cabo en dos grandes áreas: la llamada información institucional ${ }^{4} \mathrm{y}$ la calificada como información de emergencias; esta última tiene una doble función a considerar: la que coadyuva con la seguridad de personas, bienes y medio ambiente, y la relativa al derecho humano de los ciudadanos a estar informados sobre hechos relacionados con los sucesos que inciden, o pueden incidir, en la vida cotidiana tanto a nivel individual como colectivo, "La información de las cuestiones que afectan a la comunidad hace posible la existencia de la propia comunidad. Afirmar, pues, que la información es el objeto de un derecho humano, era una conclusión obligada...” (Soria, 1991, p. 10).

De forma simplista y resumida, se puede decir que el mecanismo y estructura del sistema que gestiona la Información Pública, en la Administración General del Estado, se fundamenta en el principio de que cada departamento ministerial es responsable de la información que genera y de la que le afecta, constituyéndose cada uno en fuente de información (Real Decreto 199/2012, artículo 4.5). También conviene decir que cuando se trata de dar respuesta a una situación derivada de una catástrofe o emergencia, la gestión de la comunicación queda a cargo del Director del plan de la emergencia correspondiente auxiliado por su órgano de comunicación. Pero salvo en riesgos muy concretos, como los derivados de radiaciones nucleares, la Administración, no suele disponer de órganos de comunicación específicos ni planes de comunicación de emergencia adecuados.

Esta afirmación se fundamenta en los datos obtenidos en sucesivas encuestas realizadas en los años 2000, 2007 y 2013 y que se reflejan en el cuadro 1. La carencia generalizada de estos planes de comunicación suele ser el resultado del carácter de provisionalidad de los DIRcom en sus puestos, pues suelen ser elegidos por los políticos de turno bajo la denominación de cargo de confianza, de forma que cuando estos dejan sus cargos también lo hacen los DIRCOM.

Esta continua mudanza deriva en que la política de comunicación, en la mayoría de las instituciones, puede ser tildada de cortoplacista y, por ello, llena de obstáculos para seguir una adecuada trayectoria comunicacional

3 En esa gestión del Gobierno se incluye: "la actividad comunicativa; esto es, aquella actividad que, ordenada y orientada a la difusión de un mensaje común y veraz, ajeno a la mera opinión política, persigue dar a conocer a los ciudadanos los servicios que presta y las actividades que desarrolla la Administración" (Tribunal de Cuentas, 2011).

4 No existe una definición legal relativa a este término. Para tener más información y comprender el alcance de este concepto, es conveniente remitirse a lo que se dice en el Artículo 6 de la Ley 19/2013, del 9 de diciembre, de transparencia, acceso a la información pública y buen gobierno (Jefatura del Estado. BOE núm. 295, del 10 de diciembre de 2013). 
acorde con los servicios que debe prestar; situación que provoca, en las Autoridades y los DIRcom, la búsqueda de objetivos comunicacionales con mayores réditos políticos que los que se derivan de aquellos que persiguen aumentar la resiliencia de la población.

\section{Cuadro 1. ¿Dispone su organismo de un Plan de Comunicación de Crisis?}

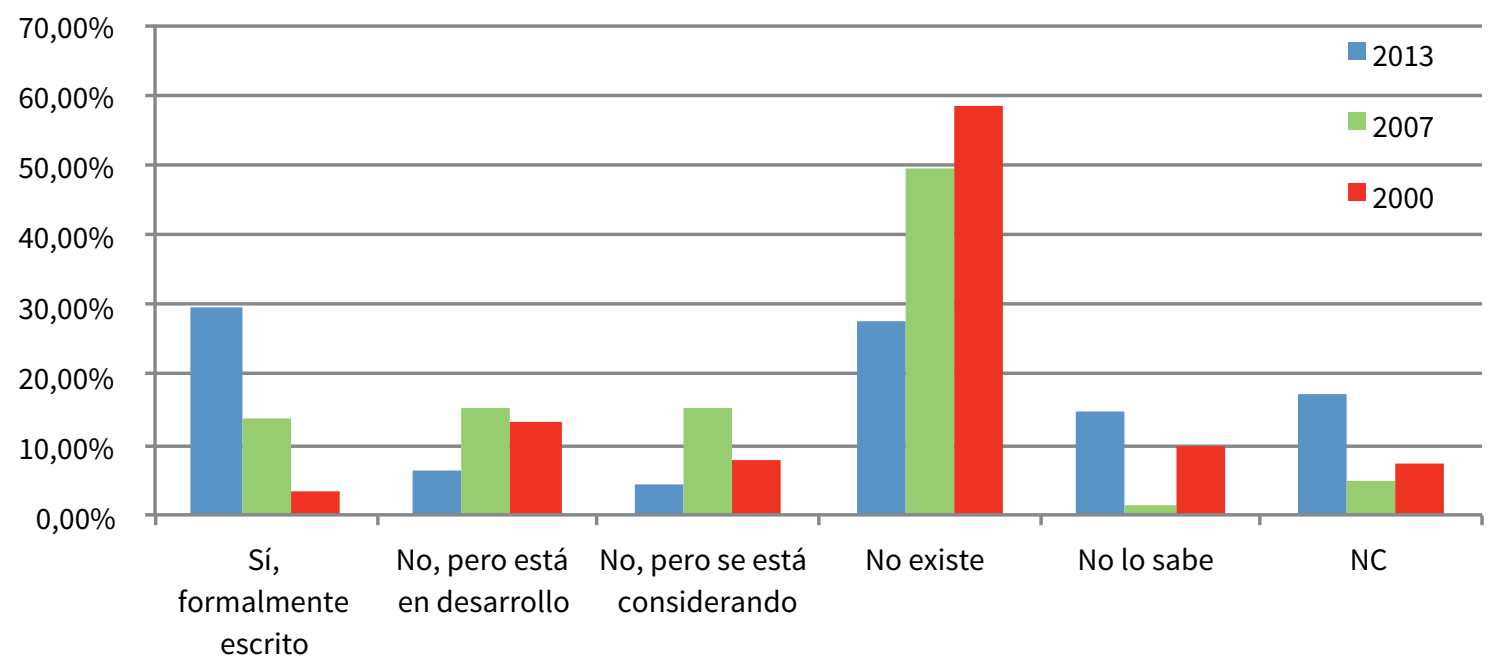

Fuente: Ibáñez, 2014, p. 360.

Así, en el informe anual de Publicidad y Comunicación Institucional de 2014 se dice que, al menos desde el año 2004, no se ha hecho ninguna campaña de comunicación para "Advertir de la adopción de medidas de orden o seguridad pública cuando afecten a una pluralidad de destinatarios"; pero si se estudia con detenimiento todo el documento se detecta con facilidad que gran parte de los ciento cuarenta millones de euros invertidos, solamente en el año 2014, han perseguido objetivos marcadamente políticos, demostrando así que la función pública de informar suele ser utilizada con mayor profusión para la promoción social de los responsables políticos.

\section{Los órganos de comunicación en la Administración y el periodismo de fuentes}

Los componentes de los órganos gestores de la Información Pública son los que en la Administración ejercen el llamado periodismo de fuentes. Este personal tiene ciertas singularidades que lo distingue de sus homólogos en la actividad periodística privada. Del estudio al que nos venimos remitiendo, realizado entre las principales instituciones de la Administración General del Estado que dan respuesta a este tipo de situaciones infaustas, cabe traer a colación algunos de los puntos investigados para aportar luz al asunto. 


\subsection{La denominación del puesto de trabajo}

Si en el mundo empresarial el término "Director de Comunicación" es asumido sin reservas, en la Administración se encuentran reticencias para emplear este término con base en la personalidad jurídica y estatus que entraña el cargo de Director, particularmente entre los funcionarios. Lo que ha llevado a la coexistencia de múltiples denominaciones contabilizándose veintidós, a saber:

Asesor, Asesor del Gabinete Técnico, Asesor Técnico, Asesor Jefe de Comunicación, Asesora de Comunicación y Gabinete Delegado, Consejero Técnico, Director de Área, Directora de la Oficina de Relaciones Informativas y Sociales, Director de la oficina de Comunicación y Relaciones Institucionales, Director de Comunicación, Jefe de la Oficina de Comunicación, Jefa de Prensa, Jefe de Prensa de la Oficina de Comunicación del Ministerio de..., Jefe del Gabinete de Comunicación, Jefe del Gabinete de Prensa, Periodista del Gabinete de Prensa, Jefe Unidad Protección Civil, Personal de Confianza o Asesoramiento Especial, Responsable prensa, Subdirector General de Información Nacional, Subdelegado del Gobierno de España, Titulado Superior de Gestión y Servicios Comunes en Gabinete de Prensa (Ibáñez, 2014, p. 343).

\subsection{Formación académica del personal que ejerce el periodismo de fuentes en la Administración}

Cuadro 2. Titulación académica del DIRcom

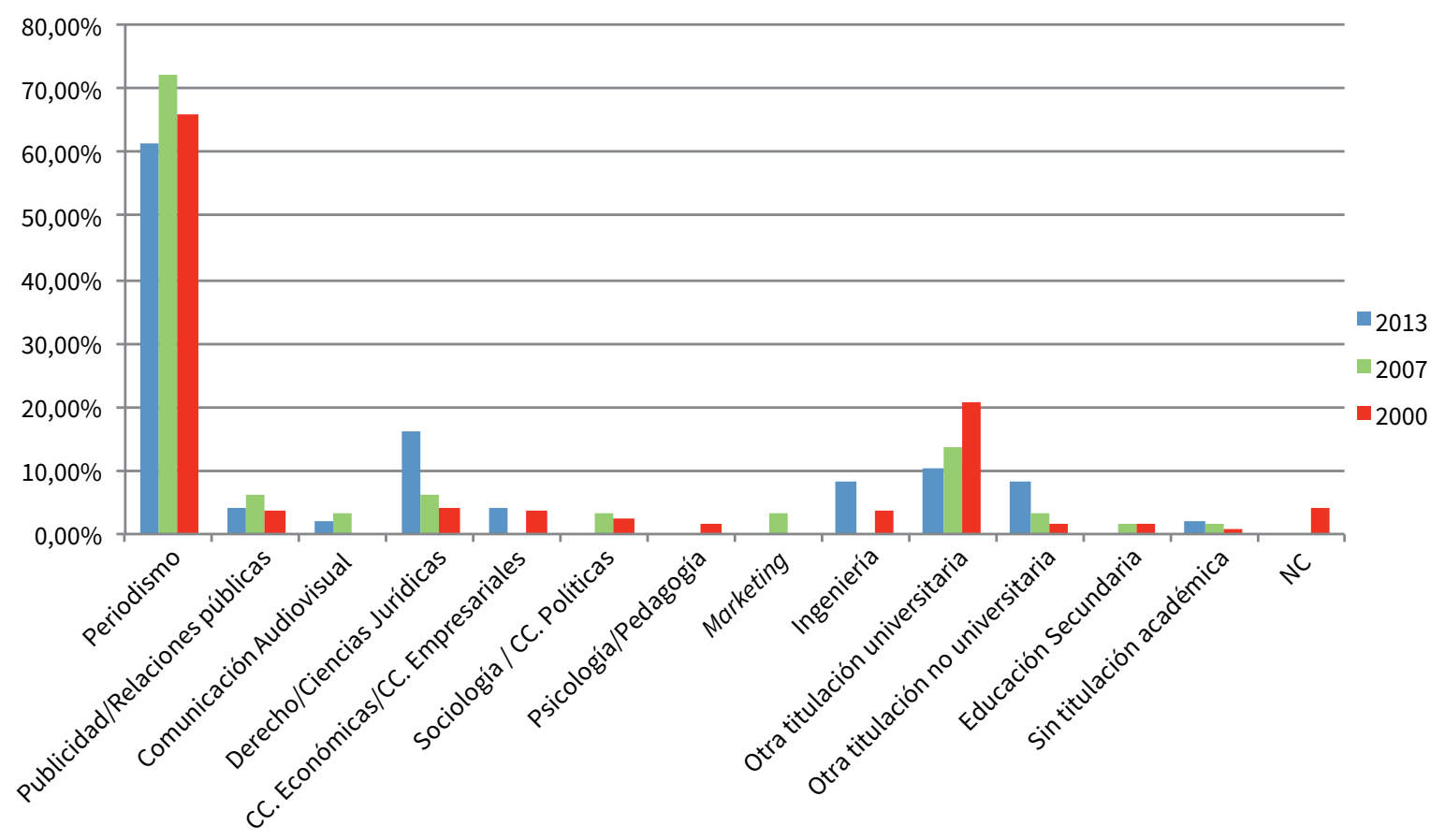

Fuente: Ibáñez, 2014, p. 348. 
Otro punto que diferencia a la Administración del mundo de la actividad privada en este campo, es que la elección del titular del órgano de comunicación (el DIRсom) se hace por el sistema de libre designación sin la obligatoriedad de ser funcionario ni tener especialidad alguna para desempeñar esta actividad (Ley 30/1984, Artículo 15). En este sentido, los datos del cuadro 2, demuestran que hay titulares de estos puestos con más de una titulación mientras que existen otros sin ningún tipo de titulación académica.

El aumento de personal sin cualificación académica, o poco cualificado, no se entiende si se considera que una de las funciones del DIRCom es relacionarse en la toma de decisiones con los órganos representativos de la institución para asesorar en cuestiones de imagen y relaciones institucionales, entre otras. Aunque podría pensarse que estos resultados responden a una distorsión temporal, la tendencia al incremento de personal poco cualificado, $1,7 \%$ en el año 2000 , 3,10\% en el año 2007 y 8,16\% en el 2013, hacen desechar esta posibilidad.

\section{Cuadro 3. Titulación académica del personal que compone el órgano de comunicación}
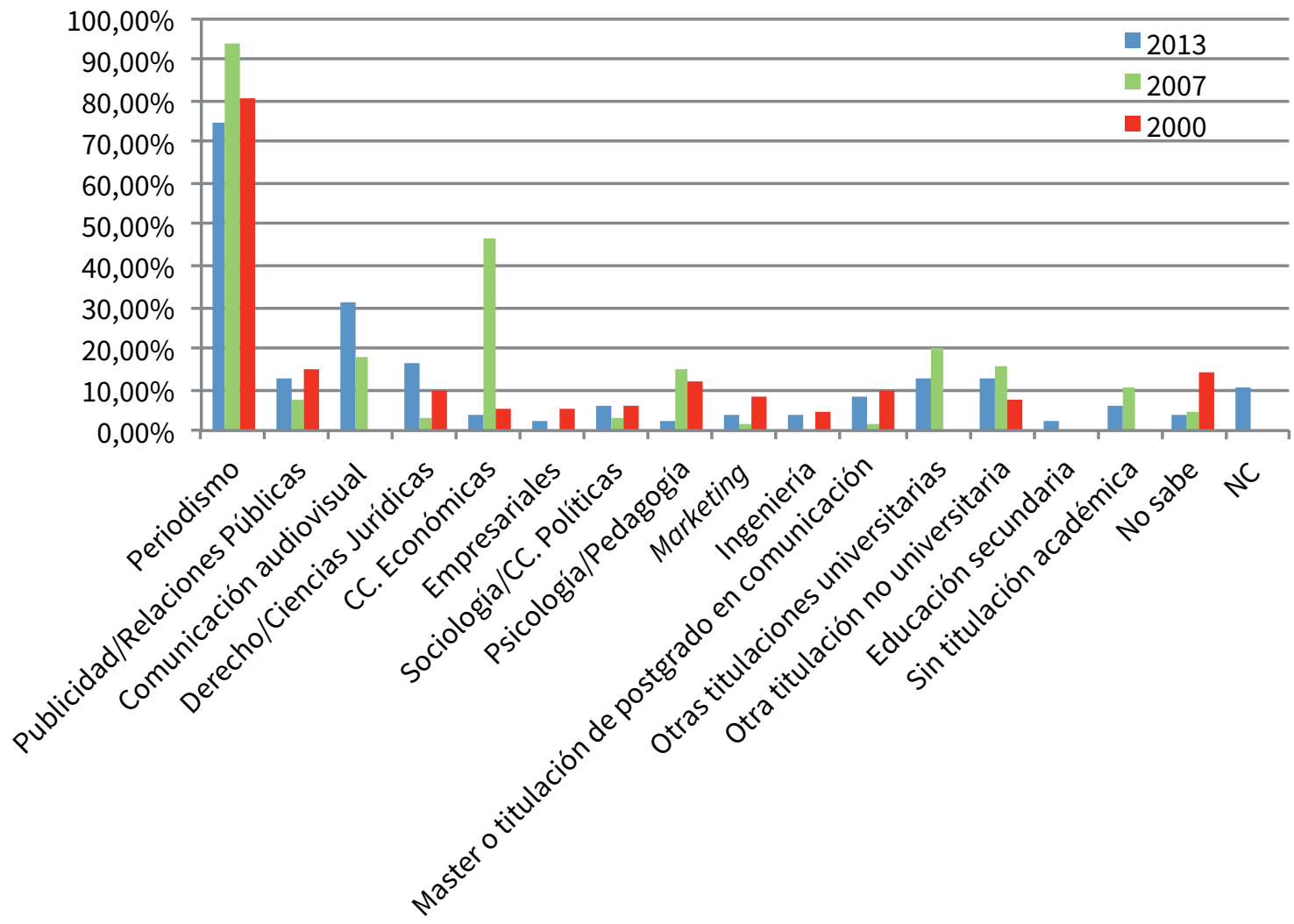

Fuente: Ibáñez, 2014, p. 353.

En el cuadro 3, relativo a la titulación académica del resto del personal que trabaja en el área de comunicación, se ratifica y aumenta la tendencia observada en el anterior. La profesión dominante es la de periodismo, los 
tres estudios lo avalan con un $75 \%$, un $93,8 \%$ y un $80,8 \%$ respectivamente entre los años 2013 y 2000; Comunicación Audiovisual, en 2013, queda en segundo lugar, dominando sobre el resto de profesiones.

Pero al igual que en la pregunta sobre la titulación académica del DIRcom, vuelve a resaltar el conjunto formado por: Otra titulación no universitaria, Educación Secundaria y Sin titulación académica; y si en el caso del DIRcom suponía un 10,2\%, para el resto del personal que compone el órgano de comunicación se eleva al 20,83\%. Las mismas consideraciones que se han hecho con el DIRcom, son aplicables para el resto del personal. Si bien es cierto que se debe tener en cuenta que el llamado personal auxiliar parece que podría estar exento de ser especialista o ser conocedor del mundo de la comunicación, no es menos cierto que la sensibilidad y trascendencia en la gestión de la comunicación no permite ningún tipo de error en el desarrollo de esta función.

Si en años venideros se ratificase o aumentase esta tendencia sería preocupante, pues ello redundaría en grave perjuicio para la función pública de informar dado que a la falta de cualificación profesional, siempre censurable en el ejercicio de la función pública, se une el alto grado de visibilidad a que está expuesto este personal en el desempeño de la función pública de informar.

Con respecto a la formación continua y especializada que debe recibir el personal que puede ejercer labores de comunicación en situaciones de emergencia, se debe señalar que no ha estado reglada ni fomentada. En unos casos se ha fiado de la experiencia personal, en otros la formación impartida en organismos como la Escuela Nacional de Protección Civil y Emergencias o el Instituto Nacional de Administraciones Públicas, y en los menos en universidades como la Complutense de Madrid.

Por lo común, las principales tareas para más del $75 \%$ de los componentes de estos órganos de comunicación son las de "comunicación e imagen pública del cargo político máximo responsable del organismo" y la de "gestionar la comunicación de crisis y emergencias" que afecten a la imagen de dicho cargo político (Ibáñez, 2014, p. 387). Lo cual pone de relieve que, al quedar en manos de los distintos Gobiernos, la función pública de informar en situaciones calamitosas, el ejercicio del periodismo de fuentes se suele distorsionar transformándose en propaganda política 5 .

\section{El terremoto de Lorca y su gestión informativa}

La elección del terremoto de Lorca como uno de los casos de estudio se debe a las particularidades comunicacionales en que se desarrolló esta catástrofe. Se produjo en una ciudad perteneciente a una Comunidad Autónoma uniprovincial, con lo cual la gestión de la comunicación parece ser menos compleja; la formación política que gobernaba con mayoría tanto en el Gobierno de la Comunidad Autónoma de la Región de Murcia como en el Ayuntamiento de Lorca era el Partido Popular. Aunque el Gobierno Central estaba en manos de PSOE, la gestión de la emergencia, y

5 "Sin embargo, debe tenerse en cuenta que la propaganda instrumentada, de forma encubierta, en la publicidad institucional, no sólo se manifiesta al lograr impactos instantáneos en los ciudadanos, como ocurre en los periodos electorales, sino mediante la difusión de mensajes durante periodos prolongados que, en virtud de planes estratégicos de persuasión política trazados a medio o largo plazo, pretenden inducir al ciudadano hacia una determinada opción política, con independencia de que su punto culminante se alcance en el periodo electoral, la campaña o la precampaña" (Tribunal de Cuentas. Informe de Fiscalización, 2011). 
consiguientemente la comunicación, quedó bajo la responsabilidad de la Comunidad Autónoma según se dispone en el Plan Especial de Protección Civil ante el Riesgo Sísmico en la Región de Murcia (en adelante sısmimur).

Es muy importante tener en consideración que la catástrofe sucedió durante un periodo de elecciones autonómicas y municipales, y muy cercano a su finalización, hecho que mediatizó la actualidad informativa determinando la agenda de la campaña electoral durante los días previos a la votación. También hubo un conjunto de noticias extraordinarias como la muerte de Bin Laden, la ilegalización de Bildu, el escándalo Strauss-Kahn, o la crisis derivada por el brote de la bacteria "E. coli" -crisis de los pepinos-, que compitieron con las que producía el terremoto.

El terremoto de Lorca fue un conjunto de movimientos sísmicos que fundamentalmente tuvieron lugar durante la tarde del día 11 de mayo de 2011. Los primeros sismos se produjeron a las 17:05 horas con una valoración de 4.4 grados (en la escala de Richter), 35 minutos después se activó el sısmimur Nivel 1. A las 18:47 horas se produjo otro de 5,2 grados y 33 minutos después se activaría el Nivel 2. Independientemente de los daños materiales y sus calamitosas consecuencias, perecieron 9 personas y 324 resultaron heridas.

\subsection{El marco legal}

La ortodoxia legal que regula la gestión de la Información Pública ante riesgos sísmicos se encuentra perfectamente determinada en el Punto 7.1. y en el anexo 16 del sısmimur de la siguiente forma:

El Director del plan sIsmimur es el Consejero de Presidencia y por delegación el Director General de Protección Civil. (...) la responsabilidad de transmitir información a la población es de la Dirección del Plan y se realiza a través de su Gabinete de Información. Toda la información deberá generarse en dicho centro, debiendo ser veraz y contrastada y que las directrices y consignas sean únicas y congruentes. (...) la información a la población es una medida de protección de importancia trascendental dada las consecuencias negativas que pueden tener determinadas conductas sociales, debidas a la falta de información o de informaciones incorrectas en situaciones de emergencia (sISMIMUR, 2006).

De igual manera, en los puntos 7 y 9 del referido texto legal se establece la persona en quien debe recaer la responsabilidad de ser DIRcom durante la emergencia sísmica, así como los integrantes del órgano de comunicación en los diferentes niveles que se puedan decretar durante el suceso. También se definen las funciones que debe desarrollar y el conjunto de equipos de trabajo que, dependientes de este Gabinete de información, deberán reforzar su labor en caso de que se decretase el Nivel 1.

Pero en lo que toca a la Información Pública, se debe decir que en este sISMImuR no se contempla ningún Plan de Comunicación de Emergencia o, cuando menos, un plan derivado del "Plan de coordinación informativa en situaciones de emergencia” al que se alude en el punto 5 del Plan Estatal de Protección Civil ante el Riesgo Sísmico. Otra carencia significativa es que en las fechas que se produjo la catástrofe, el Ayuntamiento de Lorca no disponía del correspondiente "Plan de Actuación de Ámbito Local frente al Riesgo Sísmico en Lorca" (sISMILoR), dicho plan no se aprobó hasta mayo de 2012. Dato de gran relevancia a tener en cuenta a la hora de analizar la efectividad y el cumplimiento de la legislación por parte de las instituciones durante el terremoto de Lorca.

Por último, llama poderosamente la atención que para gestionar la Información Pública en los documentos legales aludidos se emplean términos como: "Plan de coordinación informativa en situaciones de emergencia", "Plan de 
Coordinación y Apoyo de coordinación informativa en situaciones de emergencia", "Equipo de atención informativa a los medios de comunicación", "Unidad de Respuesta Vocal”. El empleo de forma predominante del vocablo "coordinación", unido a lo que se determina con respecto a la Información Pública en estas normas legales, pone a las claras que en este tipo de riesgos, para la Administración, la función pública de informar consiste en una mera labor de distribución de datos con la única finalidad de atender a los medios de comunicación, olvidando y haciendo dejación de la función pública de informar al no entender que la Administración es fuente de información por sí misma; la principal fuente de información en este tipo de situaciones y que por ello está obligada a ejercer el periodismo de fuentes. Lo cual permite vislumbrar la falta de conocimientos del legislador en materia de Información Pública así como el premeditado divorcio y falta de interés existente por parte de los responsables de la Administración en un asunto de este calado, sobre todo si se tienen en cuenta que para riesgos derivados de radiaciones nucleares, la gestión de la Información Pública está perfectamente reglada desde hace años dando unos excelentes resultados.

\subsection{La información publicada por las Administraciones y la prensa escrita durante la gestión de la catástrofe}

Antes de abordar el asunto conviene decir que en la zona de la catástrofe se interrumpió con carácter preventivo el suministro eléctrico y que la telefonía móvil se vio saturada. De esta forma, es fácil deducir que, en los primeros momentos, la información de emergencia para la población afectada por el sismo, no cumplió su finalidad adecuadamente al no poder ser recibida por los públicos a los que se pretendía dirigir. El único medio de comunicación social que cumplía de forma limitada su cometido en la zona afectada era la radio. Por las mismas causas, en la zona, internet no funcionaba y las redes sociales no tuvieron la efectividad acostumbrada al quedar inicialmente colapsada la telefonía móvil. Todo lo cual impidió que durante los primeros momentos la información a la población cumpliese la misión transcendental que le otorga el ya referido sISmImUR.

\subsubsection{La Información Pública emitida por el Ayuntamiento de Lorca}

En ese estado de cosas, a la Administración Local le resultó prácticamente imposible, en un primer momento, organizar la Información Pública a la población; muy probablemente como consecuencia de la inexistencia del Plan de Actuación Municipal en la ciudad de Lorca que, como ya se ha señalado, para cumplir con la legalidad el Ayuntamiento aprobó un año después de ocurrido el terremoto.

Durante las primeras horas, ninguna fuente oficial del Consistorio fue capaz de comparecer públicamente ante la nación para dar a conocer lo que estaba ocurriendo. Las declaraciones que el Alcalde de Lorca hacía en la zona afectada no tuvieron la difusión deseada en los medios de comunicación de alcance nacional, pues hasta el día doce no se emitieron imágenes televisivas, a nivel estatal, en las que el primer edil diese cuenta de lo ocurrido en la localidad. Tampoco la página web del Ayuntamiento fue capaz de explotar las posibilidades que ofrece internet para estos casos. Fue sorprendente el que Televisión Española estuviese realizando un programa en directo en Lorca con un equipo móvil y retransmitiese a todo el mundo unas llamativas escenas en las que se veía derrumbarse un campanario, y que el órgano de comunicación del Ayuntamiento no utilizase las posibilidades que podía ofrecerle esta circunstancia para que el Alcalde se dirigiese a España y al mundo entero haciendo unas primeras declaraciones; sobre todo si se tiene en cuenta que el primer edil trataba de informar a la población de forma directa y en persona allá por donde pasaba. Lo anterior

\section{4}


es achacable al desconcierto del momento, la poca planificación y la falta de recursos básicos asignados previamente para este tipo de situaciones; pues una vez estabilizada la situación inicial, y gracias a las unidades móviles que todos los medios de comunicación enviaron a la zona afectada, la Corporación Local emitió información abundante y fluida.

\subsubsection{La Información Pública emitida por la Administración Autonómica}

La gestión comunicacional por parte de la Oficina de prensa de la Comunidad Autónoma, constituida de forma improvisada en órgano de comunicación del sIsmımUR, tampoco fue ágil en la difusión de datos a la prensa ni a la población. Según un documento emitido por la Dirección General de Comunicación de la Comunidad Autónoma Región de Murcia relativo a la actividad desarrollada durante la catástrofe, hasta las 20:00h del día once no se emitió la primera nota de prensa y hasta las 21:00h no se convocó a los medios de comunicación para informarles sobre los datos disponibles (Ibáñez, 2014, p. 325 y siguientes). Convocatoria poco práctica pues los servicios informativos de todos los medios de comunicación, entre las 20:00h y las 21:00h, habían difundido gran cantidad de noticias al respecto teniendo como fuentes de información al propio Alcalde de Lorca, a la Delegación del Gobierno y a los periodistas desplazados a la zona. No existe constancia pública del número y contenido completo de las notas de prensa emitidas por la Comunidad Autónoma hasta la desactivación del sismimur en el mes de diciembre, pues en la página web ni se publicaron ni se puedieron localizar.

De los datos aportados en el documento aludido se puede apreciar la buena voluntad y el esfuerzo de los componentes de la Oficina de prensa del Gobierno de la Comunidad Autónoma; también se observa la improvisación y el desconocimiento de lo que se determinaba en el sismimur. Todo lo cual da una idea de la forma poco ortodoxa con que se gestionó la información, dando a entender que más que como fuente de información de la Administración, la Oficina de prensa se comportó únicamente como un órgano desde el que se suministraba a las redes sociales y a los medios de comunicación privados información de carácter político-institucional más que de emergencia (Ibáñez, 2014, p. 329).

\subsubsection{La Información Pública emitida por la Administración Central}

La Administración central tampoco gestionó adecuadamente la Información Pública, pues ante el imperativo legal de ser apoyo y complemento de la Comunidad Autónoma en esta materia, se limitó a emitir el día once tres notas de prensa en la página web de La Moncloa en las que no figura hora de emisión. La descoordinación en la gestión de la Información Pública se puso de manifiesto el mismo día doce con la difusión del desglose de personal y material empleados en la respuesta a la emergencia durante los primeros momentos, pues los datos difundidos por la Dirección General de Protección Civil y Emergencias y los expuestos por La Moncloa en su nota de prensa ofrecen notables discrepancias. (Ibáñez, 2014, p. 314)

Con posterioridad, los diversos Ministerios implicados publicarían veintiséis notas de prensa más. El contenido de la mayoría de ellas se refería a cuestiones económicas y a la reconstrucción. A partir del domingo veintidós de mayo, día de los comicios municipales y autonómicos, no se publicaron más que cuatro notas de prensa relativas a la recuperación de las infraestructuras o compensaciones económicas.

Estas circunstancias motivarían el que los datos publicados por la prensa escrita tuviesen, prácticamente, la misma actualidad que los datos emitidos por el Gobierno Central en su página web a través de sus notas de prensa. Hecho que demuestra que la Administración Central no ejerció como fuente de información. 


\subsubsection{La Información Pública emitida por los medios de comunicación privados. La prensa escrita}

El conjunto de factores comunicacionales descritos provocaron que, inicialmente, la difusión de datos y noticias relativas a la emergencia se limitasen a lo transmitido por Televisión Española a través del programa "España directo", que se encontraba emitiendo desde la ciudad de Lorca. A las repetitivas imágenes de la caída de un campanario, que puso en riesgo la vida del reportero, les siguieron gran cantidad de imágenes y datos sobre lo que estaba sucediendo difundidos por todos los medios de comunicación de ámbito nacional, hasta el punto de que fueron los telediarios de la noche los encargados de informar sobre los hechos al resto de la nación.

Serían los diarios digitales los primeros en publicar las novedades que iban aconteciendo, principalmente a través del denominado "periodismo ciudadano", de esta forma se adelantaban a la página web de La Moncloa. En cuanto a las publicaciones en papel, lo primero que llama la atención es que no se ha encontrado ningún dato publicado que ofrezca un marcado carácter negativo, ni que ponga en tela de juicio la gestión de la respuesta a la catástrofe por parte de las diferentes Administraciones o actores implicados, muy al contrario, las críticas fueron muy favorables y positivas.

Cuadro 4. Número de artículos publicados en los diarios y de notas de prensa del Gobierno Central

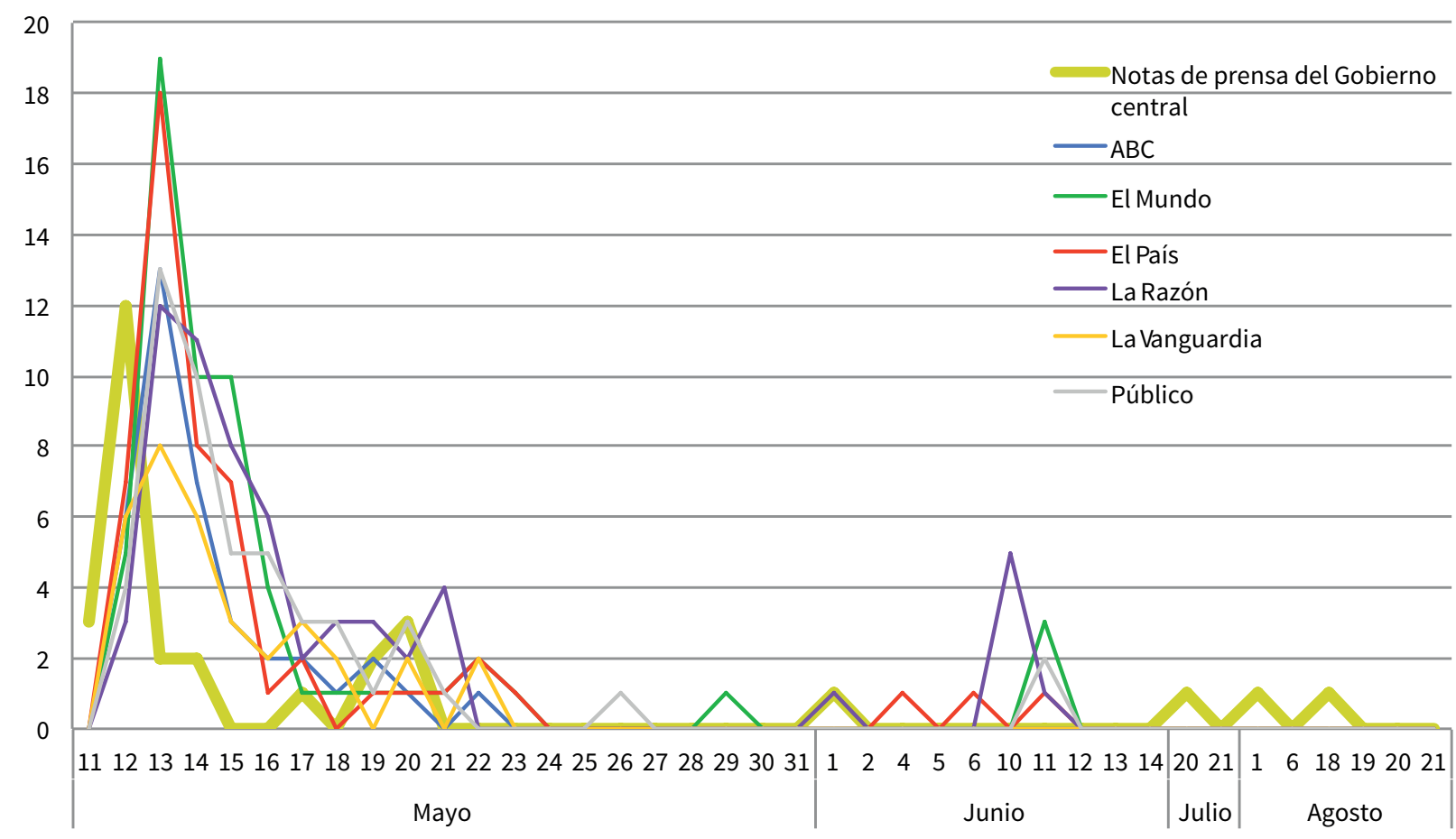

Fuente: Ibáñez, 2014, p. 469.

La información y datos publicados en la prensa escrita, y por ilación en el resto de los medios de comunicación, durante los primeros momentos, consistieron en la difusión de asuntos anecdóticos. Pasadas las primeras 
horas, se fue conociendo el alcance de la catástrofe a través de las notas de prensa y los "resortes" que suelen utilizar los profesionales de los medios y los DIRcom involucrados en la emergencia. El cuadro 4 demuestra que la prensa escrita fue a "remolque" de los datos emitidos por la Administración durante los dos primeros días para tomar la iniciativa en días sucesivos al tiempo que la Administración, haciendo dejación de la función pública de informar, no emitía notas de prensa en su página web.

El periodismo de fuentes, que debería haber sido practicado por los DIRcom pertenecientes a la Administración, se limitó a la publicación de ditirambos ensalzando a la Autoridad de la cual dependían, llegándose hasta el punto de que el número de vocablos/referencias publicados en las notas de prensa del Gobierno Central y los diarios de información general demuestran que las referencias al Presidente del Gobierno, componentes del Gobierno o Jefe de la oposición preponderaron sobre los verdaderos protagonistas: bomberos, Cruz Roja, Cuerpo Nacional de Policía, Policía local, Guardia Civil, componentes de las FFAA, servicios de Protección Civil y Emergencias, voluntarios, etc. (Ibáñez, 2014, p. 471).

\section{La crisis del virus del Ébola y su gestión informativa}

La crisis del Ébola es el segundo caso práctico escogido con base en la gran influencia que ejerció la opinión pública en el asunto, así como de la inobservancia de la ortodoxia legal en materia de gestión de la Información Pública por parte de las Autoridades implicadas.

Las primeras noticias que aparecen en la prensa española, relacionadas con los cooperantes españoles contaminados por el virus, se remontan al 4 de agosto de 2014 con titulares como este: "Dos religiosos españoles, aislados en Liberia a causa del virus del Ébola"6. La noticia adquiriría mayor relevancia al conocerse la petición formulada por la Orden Hospitalaria de San Juan de Dios para repatriar los enfermos; a esta solicitud se le unió una campaña comenzada el mismo 4 de agosto, avalada por 30.000 firmas desde Change.org. El día 5, el Gobierno decide la repatriación de los dos religiosos en un avión medicalizado del Ejército del Aire, ingresándolos en el hospital Carlos III de Madrid; el 12 de agosto Miguel Pajares, uno de los religiosos, fallece.

El 21 de septiembre se vuelve a poner en marcha el protocolo para traer a España, desde Sierra Leona, al religioso y médico Manuel García Viejo, también infectado de Ébola; pero cuatro días después fallece. El 6 de octubre se confirmaba que la auxiliar de enfermería Teresa Romero, que había formado parte del equipo que atendió al enfermo, estaba contaminada de Ébola. El marido de la enferma, Javier Limón, fue sometido a cuarentena en el Carlos III junto a 52 personas más que habían mantenido contacto con la auxiliar de enfermería.

\subsection{El marco legal en gestión de la Información Pública durante la crisis del Ébola}

Durante toda la crisis en España no se había decretado oficialmente ningún tipo de "alarma" o "emergencia", calificando la situación como "alerta sanitaria", de lo que se infiere que la Dirección (el mando único) en la gestión de la "alerta" era responsabilidad de la titular del Ministerio de Sanidad, a través de su Gabinete de Comunicación.

6 Para ver la noticia completa visitar el enlace: http://www.europapress.es/sociedad/noticia-dos-religiosos-espanoles-aislados-liberia-causa-virus-ebola-20140804130043.html 
Sin embargo, la difusión de la mayoría de noticias tuvo origen en más de setenta organismos pertenecientes a las Administraciones y organizaciones civiles, que mediante 130 de sus componentes emitieron la información con la que todos los medios de comunicación confeccionaron multitud de noticias en espacios televisivos y de radio. De esta forma, no se cumplimentó el precepto legal por el cual la portavocía en estos casos debe ser la única que suministre, a los medios de comunicación y a la ciudadanía en general, la información relativa al acontecimiento.

Para ilustrar el asunto cabe traer a colación las declaraciones hechas el día siete de agosto por la directora general de Salud Pública, Mercedes Vinuesa, en rueda de prensa, desencadenando una crisis mediática al decir que el Gobierno gestionaría con la Orden de San Juan de Dios los gastos ocasionados por haber sido ella «quien ha solicitado la repatriación». El asunto se complicó mediáticamente de tal forma que tuvo que ser el mismo presidente del Gobierno, Mariano Rajoy, quien saliese al paso el día 8 desde Mallorca confirmando que sería el Gobierno quien costease el operativo de repatriación. También fueron muy notorios los comentarios hechos por el consejero de Sanidad de la Comunidad Autónoma de Madrid entre los que cabe recordar el reproche que hizo a la auxiliar de enfermería contaminada diciendo algo parecido a que «para quitarse o ponerse un traje de protección no hace falta un máster», declaración que motivaría la dimisión del consejero.

\subsection{La información difundida y la publicada durante la crisis}

\subsubsection{La información difundida por la Administración}

La Autoridad sanitaria no utilizó los medios disponibles (Dirección de Comunicación, página web y redes sociales) para difundir a la población la Información Pública a que estaba obligada. Como se puede observar en el número de notas de prensa emitidas por los distintos Ministerios implicados en la crisis, reflejadas en el cuadro 5 , solamente cuando irrumpió en escena la Vicepresidenta del Gobierno - 10 de octubre- haciéndose cargo de la gestión de la crisis, se comenzó a cumplir la normativa en lo que toca a la función pública de informar y con ello a practicarse el periodismo de fuentes por parte de la Administración.

El rango superior de la Vicepresidenta sobre todos los titulares de los Ministerios implicados permitió unificar la portavocía, al tiempo que se utilizó a los componentes del Comité especial para la gestión del Ébola como portavoces que, con una misma voz y un mensaje homogéneo, difundieron a todos los medios de comunicación los datos oportunos. Esta iniciativa fue complementada con la difusión, en la página web del Ministerio de la Presidencia, de una serie de comunicados diarios con los que se observaba lo que dispone la ortodoxia legal para la actividad informativa.

Durante la primera repatriación, el Ministerio de Sanidad emitió una única nota/comunicado de prensa el 9 de agosto en su página web titulada: "El Ministerio de Sanidad autoriza la importación del fármaco ZMapp para el tratamiento de la infección por el virus Ébola"'. La lectura somera de la nota da a conocer la falta de rigor al confeccionarla, demostrando también la poca relevancia que el Ministerio de Sanidad daba a la difusión de Información Pública sobre el asunto. A la criticable redacción (incluso le faltaba una letra: "El medicamento ya ha llegado a Hospital..."), se debe añadir que el mensaje que difundía hacía referencia a cuestiones meramente administrativas, poco útiles

7 Para ver la nota completa visitar el enlace: http://www.msssi.gob.es/gabinete/notasPrensa.do?id=3373

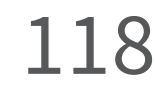


para la población; no estaba desagregado y, lo más importante, no contenía medidas preventivas que coadyuvasen a la seguridad ni a mitigar la alarma social suscitada entre la población.

Cuadro 5. Desglose de las notas de prensa emitidas por cada ministerio en la página web de La Moncloa el año 2014 durante los meses que se indican

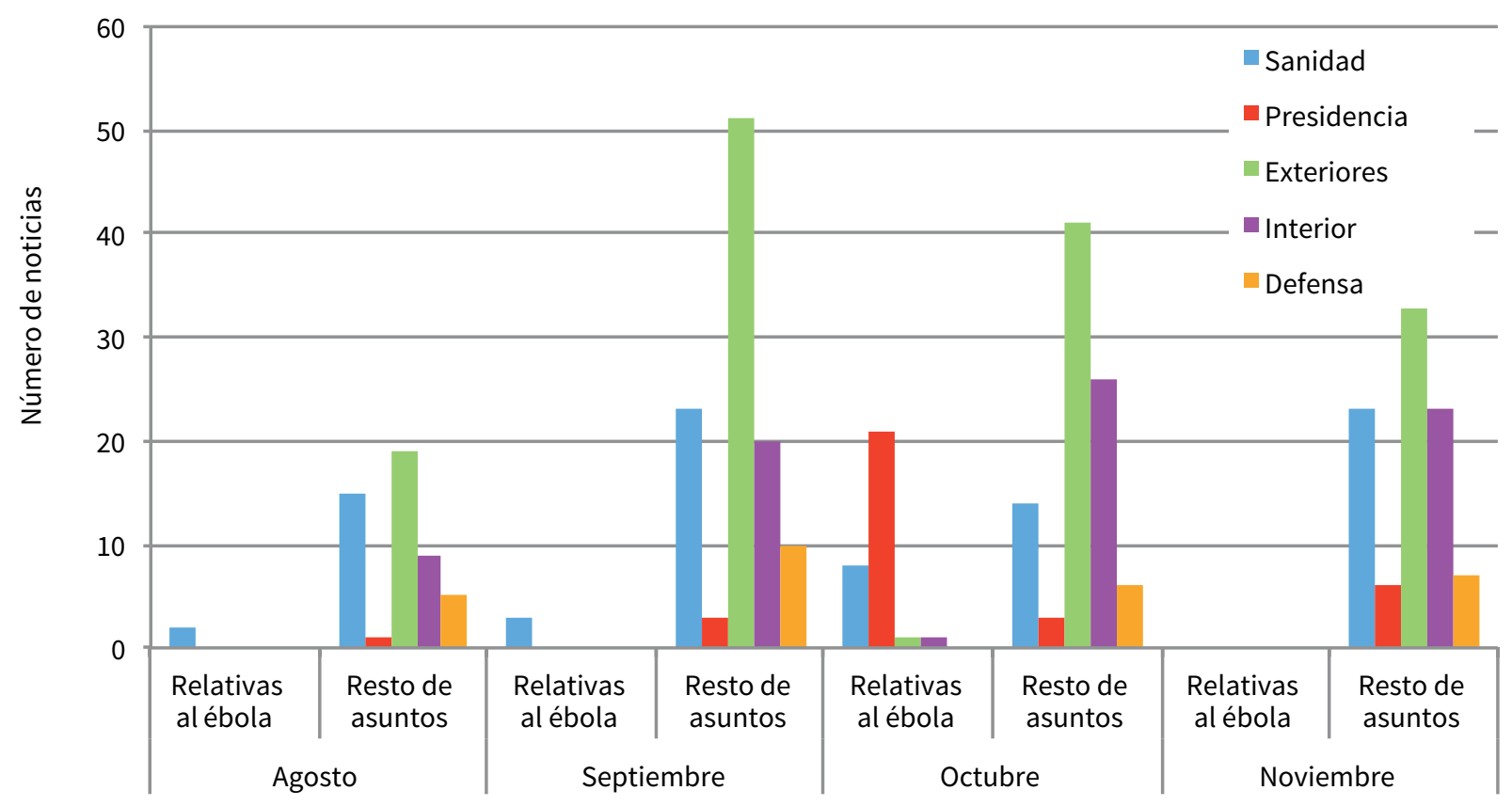

(En cada mes se diferencia entre las relativas al ébola y el resto de las publicadas)

Fuente: Elaboración propia.

Analizados los contenidos de las notas/comunicados de prensa emitidos por la Administración se desprende que en el 88,23\% de los mensajes se daba cumplimiento al mandato legal que tiene la Administración de informar. Pero también se detecta que el Ministerio de la Presidencia fue el más profuso en dar información, 21 comunicados frente a 13 del Ministerio de Sanidad; y que casi en el $25 \%$ de los difundidos por este último, su contenido era de un marcado contenido político pudiéndose calificar de "ditirambos".

Al tipificar los mensajes utilizando el sistema denominado "Un método para el estudio de la construcción mediática de la realidad" (Piñuel, Gaitán \& Lozano, 2013), se observa que principalmente a partir del 10 de octubre, casi en el 52,94 \% de las notas o comunicados "Se habla que ocurre algo a propósito de lo que acontece" (p. 174), es decir, se informaba a los ciudadanos y los medios de comunicación sobre la evolución de los asuntos relacionados con la "alerta" del Ébola, se valoraba el impacto causado en la salud de las personas hospitalizadas y, a partir del día once de octubre, se difundía información preventiva a la población que pudiese ser afectada. Por 


\section{ESTUDIOS}

último, en el 35,29\% de los mensajes "Se habla que se hace algo a propósito de lo que ocurre" (p.174), es decir, se difundían las medidas adoptadas en respuesta a la "alerta".

\subsubsection{La información publicada por los medios de comunicación}

Como resultado del escaso número de notas/comunicados de prensa y las continuas declaraciones hechas por los innumerables portavoces/informadores pertenecientes a la Administración, se produjo un aluvión de datos y anécdotas que fueron difundidos por todos los medios de comunicación, muy principalmente en tertulias televisivas y programas de entretenimiento. Debido a estas circunstancias y la dificultad que entraña la recopilación de lo publicado en los medios separando la información de aquello que puede identificarse más bien dentro de la "prensa amarilla" o del "colorín", se ha optado por investigar lo publicado al respecto en una agencia de noticias de relevancia y prestigio como Europa Press desde su página web.

Cuadro 6. Número de noticias, relativas al ÉBOLA, publicadas en la página web de la agencia EUROPA PRESS del 4 de agosto al 5 de noviembre de 2014

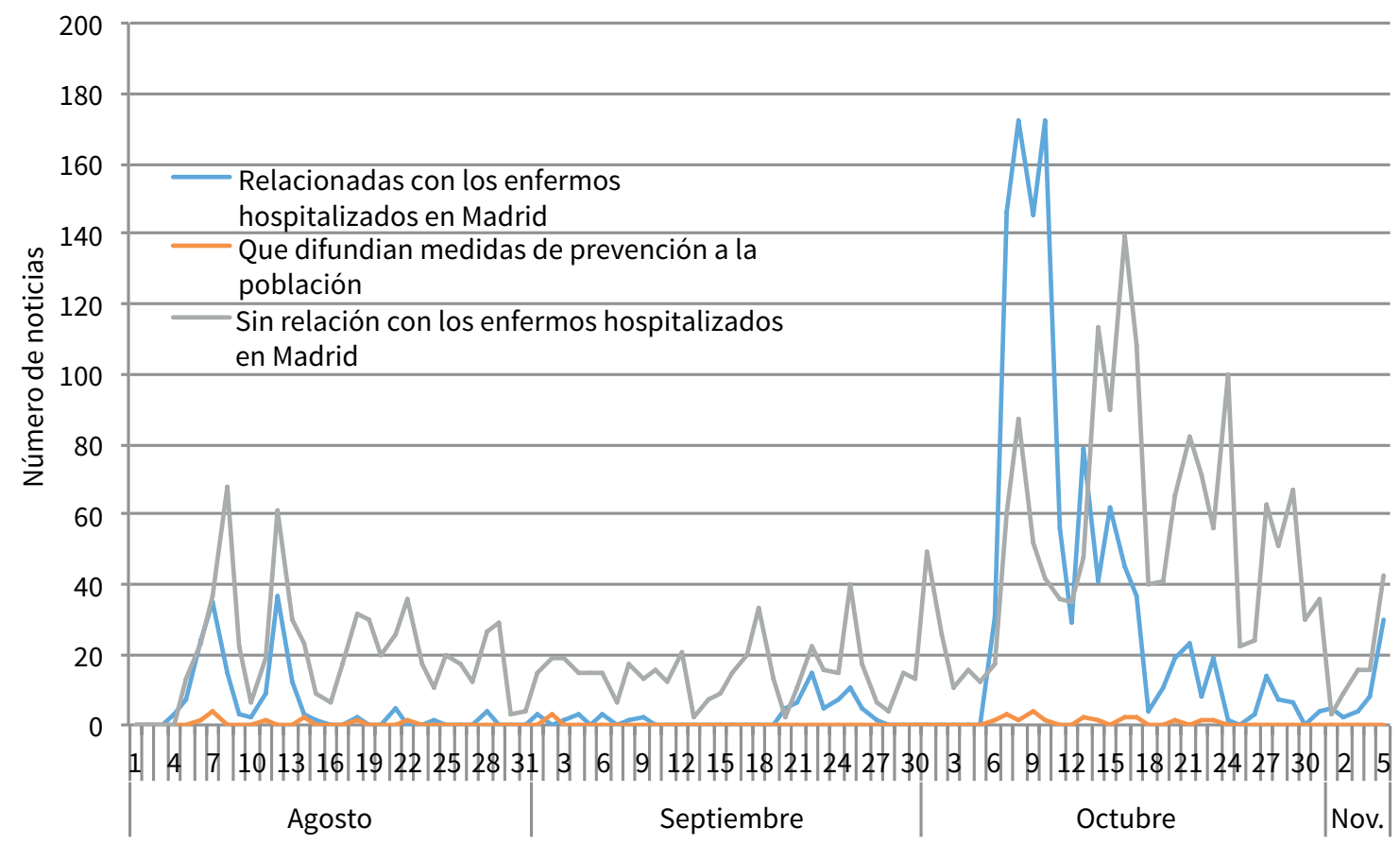

Fuente: Elaboración propia.

El cuadro 6 refleja la evolución de las noticias publicadas desde el 4 de agosto al 5 de noviembre. En él se puede observar que durante la primera fase, del 4 al 12 de agosto, en la página web de Europa Press se publicaron 390 noticias relativas al Ébola, en ellas el contenido de 137 se relacionaba de forma directa con el estado de salud 
de los enfermos hospitalizados en el Carlos III o las circunstancias en las que estaba inmerso el Sistema Nacional de Salud en Madrid con respecto al asunto.

Durante el mes de agosto destacan los días 7 y 12 con 35 y 37 noticias respectivamente, fechas marcadas por las declaraciones de la directora general de Salud Pública, Mercedes Vinuesa, y el fallecimiento de Miguel Pajares. De igual forma, entre el 21 de septiembre y el 30 de octubre, se publicaron 3167 noticias relativas al Ébola; en 1189 de ellas su contenido informaba sobre el estado de salud de los enfermos hospitalizados, las posibles personas contaminadas en Madrid, o aludían al Sistema Nacional de Salud en la Comunidad Autónoma de Madrid. Este considerable aumento de noticias, en comparación con las publicadas en la primera fase, fue el resultado de la contaminación de la auxiliar de enfermería y la poco acertada gestión de la información pública entre los días 6 y 10 de octubre por parte del Ministerio de Sanidad, hecho que motivó la aparición de numerosas fuentes de información que hacían ingobernable la gestión comunicacional.

\subsubsection{Datos demoscópicos relativos a la crisis del Ébola}

El desmesurado número de noticias publicadas incita a conocer la influencia y penetración que tuvo la crisis entre la población, pues se publicaron los resultados de gran cantidad de sondeos y encuestas hechas desde diversas plataformas y medios de comunicación. De las publicadas en internet la que más se ajusta a las finalidades del presente estudio es la denominada Percepción social sobre la crisis del Ébola (GAD3, 2014). Entre las conclusiones a que llega cabe destacar las siguientes:

Un $26 \%$ de los madrileños afirma estar preocupado por un posible contagio del virus, aunque los que consideran probable el contagio no llegan al $10 \%$.

Un 59 \% considera mucho o bastante creíble la información emitida por los portavoces sanitarios, responsables de la comunicación de la gestión del Ébola.

La información de los medios de comunicación sobre el Ébola es valorada como comprensible (61\%), alarmante (56\%), rápida (51\%), poco rigurosa (46\%). Hay disenso sobre la cantidad de información: un $37 \%$ cree que ha sido excesiva mientras otro $37 \%$ la considera insuficiente.

Si se recurre al Centro de Investigaciones Sociológicas, no se encuentra ningún estudio específico sobre el tema; únicamente los barómetros de los meses de octubre y noviembre de 2014, en las preguntas relativas a los problemas que existían en España, se incluía el término "Ébola". Los resultados permiten afirmar que la crisis del Ébola dejó de interesar una vez controlada la crisis mediática por el Ministerio de la Presidencia, mes de octubre, ya que en el mes de noviembre no se produjo resultado alguno. La preocupación demostrada entre los consultados en el único mes en que se obtuvieron resultados fue de tipo residual, $1,1 \%$ y $0,3 \%$ respectivamente, quedando en penúltimo lugar las dos opciones, "como problema existente en España" y "como problema que le afecta al ciudadano".

Este conjunto de datos demoscópicos ponen a la luz que aunque las noticias relacionadas con la crisis saturaron los telediarios, los informativos y los programas de entretenimiento televisivos, no produjeron inseguridad epidémica entre la población. Lo que apunta a que la crisis tuvo mayor eco entre los medios de comunicación que entre la ciudadanía. 


\section{Conclusiones}

Para la Administración Pública informar a la población es un mandato legal que se desarrolla en dos grandes áreas: la llamada información/comunicación institucional y la calificada como información/comunicación de emergencias. En esta última área, la Administración debe ser la principal fuente de información con base en la gran disponibilidad de medios con que el Estado las afronta y al alto grado de veracidad en la información que maneja y difunde. Esa función pública de informar se debe materializar, principalmente, mediante la práctica del llamado periodismo de fuentes.

Los órganos de comunicación pertenecientes a las instituciones y organismos oficiales, son los encargados de desarrollar esa labor informativa. Tienen la peculiaridad de que sus Directores suelen ser escogidos por el sistema de libre designación al ser considerados como cargos de confianza. El personal que compone estos órganos no suele estar formado adecuadamente para gestionar la Información Pública en situaciones de catástrofe o emergencia, hasta el punto de que hay un porcentaje elevado que no tiene una formación académica relacionada con las ciencias de la información o con las técnicas de respuesta a este tipo de situaciones calamitosas. Uno de los resultados derivados de esta disfunción es, por lo común, la ausencia de los pertinentes planes de comunicación que deben formar parte de los correspondientes planes de emergencia; planes de comunicación de los que estos profesionales suelen desconocer que es responsabilidad de ellos no solo ejecutarlos, sino también colaborar en su elaboración.

Los casos prácticos estudiados ponen de manifiesto que durante los primeros momentos de una emergencia, en cuestiones de información a la población, la improvisación suele ser el denominador común. La primera consecuencia, en ambos casos, fue la desinformación de la población afectada sobre las medidas de autoprotección que debía adoptar para aumentar su resiliencia. La segunda es el incumplimiento, por parte de la Administración, de la función pública de informar sobre los asuntos que afectaban a los ciudadanos.

Salvo en casos excepcionales como son los riesgos radiológicos en los que hay un plan de comunicación claro, la inexisencia de órganos de comunicación especializados en gestionar la Información Pública en catástrofes o emergencias hace que la labor informativa sea desempeñada por los mismos órganos de comunicación que gestionan de forma habitual la comunicación institucional, desvirtuándo los contenidos que se difunden, en ditirambos progubernamentales. Así se puso de manifiesto en el terremoto de Lorca y se volvió a reproducir en la crisis del Ébola durante la mayor parte del tiempo que duró.

Visto lo cual, no parece aventurado decir que, en situaciones de emergencia, la Administración suele ejercer la función pública de informar como altavoz de los intereses del político de turno en lugar de cumplimentar los mandatos legales de aumentar la resiliencia de la población afectada y mantener informada a la comunidad sobre las cuestiones que le afectan. Esta función debe ser ejercida de forma aséptica mediante las técnicas utilizadas por el denominado periodismo de fuentes.

\section{Referencias}

1. Asociación de Directivos de Comunicación, DIRCom. (2007). La Dirección de comunicación en las administraciones públicas: retos y oportunidades. Madrid: Instituto Nacional de Administración Pública. 
2. Ayuntamiento de Lorca. Página web. Lorca informa (2 de octubre de 2013). Recuperado de http://www. lorca.es/lorcainforma/noticias.asp

3. Canel, M.J. (2007). La comunicación de las instituciones públicas. Madrid: Tecnos.

4. Consejo de Gobierno de la Comunidad Autónoma de Murcia. (2006). Plan especial de protección civil ante el riesgo sísmico en la región de Murcia (sISMimuR). Aprobado el 20 de octubre de 2006. No fue publicado en el воRм, al no ser trámite preceptivo para su efectiva implantación.

5. Desantes Guanter, J.M. (1976). La función de informar. Ediciones Universidad de Navarra S.A. (EUNSA).

6. España, Congreso de los Diputados Pleno y Diputación Permanente. Proyecto de Ley de Publicidad y Comunicación Institucional. Sesión plenaria 114, celebrada el jueves 2 de octubre de 2005.

7. España, Dirección General de Protección Civil y Emergencias. (1991). Guía para la Comunicación de Riesgos Industriales Químicos y Planes de Emergencia. Recuperado de http://www.proteccioncivil.org/ documents/11803/22691/Gu \%C3\%ADa+para+la+comunicaci \%C3\%B3n+de+riesgos+industriales

8. España, Dirección General de Protección Civil y Emergencias. (2001). Guías Técnicas para el Análisis y la Comunicación de Riesgos. NIPO: 126-01-040-3. DL: M-54767.

9. España, Dirección General de Protección Civil y Emergencias. (2004). Análisis de la demanda de información y elaboración de un modelo guía de respuesta. (CEISE).

10. España, Jefatura del Estado. Ley 30/1984, de 2 de agosto, de medidas para la reforma de la Función Pública. Boletín Oficial del Estado 185, (3 de agosto de 1984).

11. España, Jefatura del Estado. Ley 29/2005 de Publicidad y Comunicación Institucional. Boletín Oficial del Estado 312, (30 de diciembre de 2005).

12. España, Jefatura del Estado. Ley 19/2013, de 9 de diciembre, de transparencia, acceso a la información pública y buen gobierno. Boletín Oficial del Estado 295, (10 de diciembre de 2013).

13. España, Jefatura del Estado. Ley 17/2015, de 9 de julio, del Sistema Nacional de Protección Civil. Boletín Oficial del Estado 164, (10 de julio de 2005).

14. España, Ministerio de Administraciones Públicas. Real Decreto 199/2012, de 23 de enero, por el que se desarrolla la estructura orgánica básica del Ministerio de la Presidencia y se modifica el Real Decreto 1887/2011, de 30 de diciembre, por el que se establece la estructura orgánica básica de los departamentos ministeriales. Boletín Oficial del Estado 20, (24 de enero de 2012).

15. España, Ministerio de la Presidencia. Informe anual de Publicidad y Comunicación Institucional 2014. (2014).

16. España, Ministerio de Sanidad, Servicios Sociales e Igualdad. Página web. Notas de prensa. El Ministerio de Sanidad autoriza la importación del fármaco ZMapp para el tratamiento de la infección por el virus Ébola. (9 de agosto de 2014). Recuperado de http://www.msssi.gob.es/gabinete/notasPrensa.do?id=3373

17. España, Ministerio del Interior. Resolución de 29 de marzo de 2010, de la Subsecretaría, por la que se publica el Acuerdo de Consejo de Ministros de 26 de marzo de 2010, por el que se aprueba el Plan Estatal de Protección Civil ante el Riesgo Sísmico. Boletín Oficial del Estado 86, (9 de abril de 2010).

18. Europa Press. (4 de agosto de 2014). Dos religiosos españoles, aislados en Liberia a causa del virus del Ébola. europapress.es. Recuperado de http://www.europapress.es/sociedad/noticia-dos-religiosos-espanoles-aislados-liberia-causa-virus-ebola-20140804130043.html

19. GAD3 (2014) Percepción social sobre la crisis del Ébola. Recuperado de www.gad3.com 
20. Gobierno de España. Página web de La Moncloa. Notas de prensa. Cronología del terremoto de Lorca. (30 de septiembre de 2011). Recuperado de http://www.lamoncloa.gob.es/

21. Ibáñez Peiró, A. (2014). Comunicación, Administraciones Públicas y gestión de crisis y emergencias. Universidad Complutense de Madrid. Recuperado de http://eprints.ucm.es/29450/

22. Micaletto Belda, J.P., \& Gallardo Vera, L. (2015). La comunicación institucional en la crisis del Ébola en Europa: el caso de la crisis española de 2014 en sus inicios. Revista Internacional de Relaciones Públicas. 5(9). Recuperado de http://revistarelacionespublicas.uma.es/index.php/revrrpp/article/view/316

23. Nieto, A. (1987). Cartas a un empresario de la Información. Pamplona. Editado por el autor. Madrid: Distribuido por Fragua.

24. Piñuel Raigada, J.L., Gaitán Moya, J.A., \&Lozano Asencio, C. (2013). Confiar en la prensa o no. Un método para el estudio de la construcción mediática de la realidad. Comunicación Social Ediciones y Publicaciones.

25. Santamaría, G.P. El Plan Estatal de Protección Civil ante el Riesgo Sísmico: La continuación de los Planes de Protección Civil de las Comunidades Autónomas y su aplicación práctica en el terremoto de Lorca. Dirección General de Protección Civil y Emergencias, (diciembre de 2012). Recuperado de http://www. sispyr.eu/IMG/pptx/9-ORSEC_El_Plan_Estatal_de_Proteccion_Civil_ante_el_Riesgo_Sismico_G_Santamaria.pptx

26. Soria, C. (1991) La Hora de la Ética Informativa. Editorial Mitre. Barcelona.

27. Tribunal de Cuentas. Informe de Fiscalización de los contratos de Publicidad y Comunicación Institucional suscritos por las principales Entidades locales durante los años 2005, 2006 y 2007. Aprobado en sesión de 21 de julio de 2011. 